\title{
Symptoms and Underlying Factors of Depression among Inmates in Bonga Town Correctional Center, Kaffa Zone, SNNPR, Ethiopia
}

\author{
Getachew Roba Agegnew*1; Aregash Hassen Mohammed ${ }^{2}$; Berhanu Nigussie Worku ${ }^{2}$ \\ ${ }^{1}$ Department of Psychology; Bonga college of Teacher Education, Ethiopia \\ ${ }^{2}$ Department of Psychology; Jimma University; Ethiopia \\ *Email: robagetachew@gmail.com
}

http://dx.doi.org/10.18415/ijmmu.v6i4.1026

\begin{abstract}
The main objective of this study was to examine symptoms and underlying factors of depression among inmates of Bonga Town correctional center. The institution-based cross-sectional study design was employed and through systematic sampling, 327 inmates from February to March 2017 were considered for this study. Data was collected by using a standardized self-reported questionnaire. Stepwise regression was conducted to identify associated factors. Mann Whitney U test was used to determine gender difference on symptoms of depression. The finding of this study revealed symptoms of depression (change in appetite, change in sleep pattern, loss of energy, selfdislike) prevail among inmates of Bonga Town correctional center. The level of depression was moderate 52.29\%. Pessimism ( $\mathrm{r}=.120, \mathrm{P}=.030)$, self-dislike $(\mathrm{r}=.136, \mathrm{P}=.014)$ and crying $(\mathrm{r}=.142$, $\mathrm{p}=.010$ ) were symptoms of depression associated with inmates years of incarceration. Sociodemographic factors, environmental factors were to as well as psychosocial factors were associated with depression. There was a significant gender difference in each symptom of depression; i.e female inmates suffered more than male inmates in each symptom of. Bonga correctional center communities should work cooperatively with Bonga G/Tsadik Shawo hospital to help inmates who were at risk.
\end{abstract}

Keywords: Symptoms, Depression, Beck Depression Inventory; Cross-sectional Study; Correctional Center and Inmates

\section{Introduction}

Imprisonment, like other forms of incarceration, is a significantly stressful event in an individual s life (Birmingham, 2004). Imprisonment being a form of punishment produces significant changes in one s physical, psychological, and social functioning. Despite our ability to cope and adapt as humans, traumatic incidents may change a person $\mathrm{s}$ biopsychosocial balance to 
such an extent that the memory of a particular negative event overshadows all other experiences and affects the ability to cope with reality. ((Drapalski, 2009). In the prison, however, basic human values are distorted, contributing to temporary or even irreversible psychological sequelae.

A study conducted in Ethiopia by (Bahiretibeb, Gelaye, Lemma, and Williams, 2012,p.237) revealed that the prevalence of mental distress is lower than that of Jimma and accounts $17.7 \%$. In addition, most findings found that the prevalence of depression in different parts of Ethiopia is high. For example, (Mossie, Negash, and Kindu, 2012) present their finding in a conference that held in Jimma University and the prevalence of depression in Jimma Town is high. They conduct a study on a sample of 590 by using BDI-II and they found that the prevalence of depression was $29.0 \%$.

According to National Institute of Mental Health [NIMH] 2003 (as cited in National Academy on An Aging Society [NAAAS], 2000), depression is the most severe mental problem among United State population and above 19 million adult individuals are affected by depression.

More than 10.2 million people are held in penal institutions throughout the world (2014). Among these individuals, the United States has the highest prison population of approximately 2.24 million (Walmsley. 2013). Prison settings such as overcrowding, lack of privacy, violence, social isolation, inadequate mental health facilities, and the effects of the prison sentence may lead to mental disorders among prisoners during imprisonment (WHO,2007).

Prisoners come from the community and will return to the community. Therefore, the prevention and rehabilitation of mental disorders should not be neglected in prison settings. Assessing and addressing the mental health needs of prisoners will aid in the development of appropriate policy and health services to improve the health of prisoners. These measures will further help to reintegrate inmates into community life.

Major depressive disorder (MDD), also known as depression, expressed by at least 2 weeks of low mood that is present across most situations; it is often accompanied by low self-esteem, loss of interest in normally enjoyable activities, loss of energy, pain without a clear cause (Walmsley, 2013).

The prevalence of mental health problems is higher in the prison population than in the general population (Fazel S, Seewald K, 2012). The World Health Organization estimated that, of the 9 million prisoners worldwide, at least 1 million (11\%) suffer from significant mental disorders, and the most common mental health problems are depression and anxiety (WHO,2008).

Depression is a significant contributor to the global burden of disease and affects all communities across the world. The World Mental Health Survey conducted in 17 countries found that on average 1 in 20 people reported having an episode of depression (Ministry of Home Affairs,2016). World Health Organization (WHO) states that depression is the leading cause of disability as measured by years lived with disability (YLDs) and it is the fourth leading contributor to the global burden of disease. By 2020 it is projected to reach second place in ranking (Fazel S, Danesh J, 2002).

The prison environment neutralizes the formation and development of basic human values, contributes to stigmatization, alters the convict's conduct and leads to temporary or even irreversible psychic outcome (Muakad,1998). In spite of the symptoms, feelings of inadequacy, important 
feelings in imprisoned people are anticipated suffering in life outside of incarceration, fear of family abandonment, sadness, pessimism, past failure, guilt for being absent from raising and educating their children, losing their right to the social importance of work, identity loss, social discrimination that impairs prospects for working outside of the criminal context and social recognition (Fernandes \& Hirdes, 2006,p. 418-424.).

Depression is a mental disorder characterized by sadness, loss of interest or pleasure, feelings of guilt or low self-worth, disturbed sleep and appetite, feelings of tiredness, lowering of mood and poor concentration. Depending on the number and severity of these symptoms, depression is classified as mild, moderate and severe (World Health Organization, 2019).

According to the World Health Organization (WHO), one out of nine prisoners worldwide experience a mental disorder; the majority of them suffer from depression and anxiety. The high rate of mental disorders in this population is due to factors such as overcrowding, violence, enforced isolation, lack of privacy and meaningful activity, isolation from the social norm, insecurity about the future prospect, and inadequate mental health services in prisons ( WHO,2007).

Imprisonment being a form of punishment produces significant changes in one's physical, psychological, and social functioning. Despite our ability to cope and adapt as humans, traumatic incidents may change a person's biopsychosocial balance to such an extent that the memory of a particular negative event overshadows all other experiences and affects the ability to cope with reality. ( Drapalski AL, Youman K, Stuewig J, Tangney,2009). In the prison, however, basic human values are distorted, contributing to temporary or even irreversible psychological sequelae.

The prison environment neutralizes the formation and development of basic human values, contributes to stigmatization, alters the convict's conduct and leads to temporary or even irreversible psychic outcome (Muakad,1998).

\section{Statement of the problem}

Depression is the most severe problems that occur all over the world and this disorder leads to other problems and affects an individual s life. An individual may be affected by this problem in his /her lifetime in the population; particularly in the correctional center.

There is a difference between male and female in relation to the effects of imprisonment. Hence, according to (Ulzen, Psych \& Hamilton, 1998, p.57-63), Gender differences exist with respect to the effects of incarceration on both male and female inmates. Mental health problems have been observed to be higher among incarcerated inmates compared to the general population and are a significant source of morbidity among inmates (Fatoye, Oyebanji, \& Ogunro, 2006, p.545).

A study conducted in Ethiopia by (Lemma, Gelaye, Bahiretibeb, \& Williams, 2012p.237) revealed that the prevalence of mental distress is lower than that of Jimma and accounts $17.7 \%$. In addition, most findings found that the prevalence of depression in different parts of Ethiopia is high. For example, (Mossie, Kindu, \& Negash, 2012) present their finding in a conference that held in Jimma University and the prevalence of depression in Jimma Town is high. They conduct a study on a sample of 590 by using BDI-II and they found that the prevalence of depression was $29.0 \%$. 
In relation to this, southern nation nationalities and peoples of Ethiopia region; Bonga Town correctional center was institution / correctional center in which a lot of people are incarcerated for short period sentenced to death and life sentence due to the criminal offense they made. However, not all inmates in Bonga Town correctional center are offenders. In spite, the correctional center is an ancient institution, where diverse types of people, who had run afoul of the law, some of them possibly innocent, live (Jordan, Schlenger, Fairbank, \& Caddell, 1996, p.513-519). In other word, there are inmates who were imprisoned before they are sentenced by the court and wait until they are sentenced whether they are guilty or not. Therefore, the above condition may or may not pose these inmates to have a mental disorder such as depression, psychological distress, anxiety, etc.

Therefore, conducting a study on the symptoms and underlying factors of depression among inmates in Bonga Town correctional center may help us to further understand the prevalence and underlying factors of depression among inmates of Bonga Town, correctional center. Hence, the study, therefore, seeks to answer the following research questions:

$\Psi$ What symptoms of depression prevail among inmates in Bonga Town correctional center?

$\Psi$ What are the levels of depression among the inmates in Bonga Town correctional center?

$\Psi$ What is the association between depression and inmates years of incarceration?

$\Psi$ What are the major factors to symptoms of depression among inmates of Bonga correctional center?

$\Psi$ Is there a gender difference in the prevalence of symptoms of depression among inmates of

Bonga Town correctional center?

\section{Research methods}

The institution-based cross-sectional study design was used. Hence, the study employed a quantitative research method. The target population of the study was inmates of Kaffa zone Bonga Town correctional center.

The statistics of Bonga Town correctional center during the time of conducting this research showed that there are 2,190 (106 Female and 2084 Male) inmates at the time of conducting this research. The study sample was determined according to the fine population correction (FPC) principle, postulated by Araoye (2003), if there is no reasonable estimate, a projected population of 0.5 is recommended for calculating the required sample size. However, in this study, the population was 2,190 (less than 10,000), the required sample size will be therefore calculated using the Finite Population Correction for Proportions formula:

$$
n=\frac{n_{o}}{1+\frac{\left(n_{o}-1\right)}{N}}
$$

Where, $\mathrm{n}=$ the desired sample size when population $<10,000$.

$\mathrm{n}_{\mathrm{o}}=$ the desired sample size when population is $>10,000$.

$\mathrm{N}=$ the estimated study population 2,900 in this study.

$$
n=\frac{384}{1+\frac{(384-1)}{2190}}
$$


This gave a sample size of 327 .

Systematic random sampling was done to select male inmates using the correctional center registry; because of its simplicity, easiness to apply and extends the sample to all population. It allows the researcher to add a degree of system or process into the random selection of subjects (Kothari, 2004) and using the sampling interval size calculated with the sampling fraction(K): i.e.

$$
K=N / n
$$

Where $\mathrm{N}$ is the total Population $(2,190), \mathrm{n}$ is sample size (327), while $\mathrm{k}$ is sampling interval size.

$$
2190 / 327=6.68 \approx 7
$$

Therefore every seventh (7th) inmate on the registry in both male and female sections of the correctional centers was selected. While all-female inmates were included in the sampling.

In order to collect information Beck Depression Inventory (BDI-II) in the form of a questionnaire that has been utilized to detect symptoms of depression among inmates.

Following the selection of the site of the study, a general supportive letter was written by Jimma university post-graduate office to the Kaffa zone police commission and Bonga Town correction administration for permission and was obtained to conduct the research on condition that it would not affect the institution's hierarchical organization. At the inception of data collection, the consent of participants was asked. Following this, the purpose of the study was explained to participants and they were given orientation on how to respond to the questionnaire, and before distributing the instrument.

After the data was collected, data entry and analysis was done using Statistical Package for Social Sciences (SPSS) version 20. The demographic characteristics of participants were computed by using simple descriptive statistics (percentage and frequencies). Stepwise regression was used to determine the relationship between predictor variables (factors for depression) and the outcome (symptoms of depression according to BDI-II). Nonparametric test particularly Mann Whitney U test was conducted to determine the difference between male and female on having the symptoms of depression.

\section{Result}

\section{Socio-demographic Characteristics of Respondents in Bonga correctional center.}

The total numbers of the distributed questionnaires were 327 and all questionnaire were filled completely and consistently with a response rate of $100 \%$. Among the total respondents who filled the questionnaire, 221(67.58\%) were males and the rest 106 (32.41\%) were females. The majority of respondents age was on the intervals of 26-33. This age is considered as middle adult-hood where individuals are going to be ready for the occupation, social responsibility as well as marriage. As observed from below table the majority of respondents were from Kaffa (42\%) and Menja (20.48 \%) while the rest were from Amhara, Oromo, Sheka, and others. The reason why the number of Kaffa and Menja was that this research was conducted in Kaffa zone. Regarding their years of incarceration majority of inmates are sentenced with the intervals of 2 years and a half- 5 years (35.16\%) while the rest were sentenced with the rest intervals. Furthermore, the majority of respondents in Bonga correctional center were at primary school (43.1\%) and the rest were illiterate, 
secondary school and university and college graduates. At last, the majority of respondents were divorced (33.63) and the rest were single 29.07\%.

Table 1. Symptoms of depression that prevail among inmates of Bonga correctional center

\begin{tabular}{lcc}
\hline Symptoms of depression & Frequency & Percentage \\
\hline Sadness & 138 & $42.2 \%$ \\
Pessimism & 98 & $29.96 \%$ \\
Past failures & 93 & $28.44 \%$ \\
Loss of pleasure & 141 & $43.11 \%$ \\
Guilty feeling & 146 & $44.64 \%$ \\
Punishment feeling & 61 & $18.65 \%$ \\
Self-dislike & 189 & $57.79 \%$ \\
Self-criticalness & 196 & $59.93 \%$ \\
Suicidal thoughts or wishes & 113 & $34.55 \%$ \\
Crying & 103 & $31.49 \%$ \\
Agitation & 123 & $37.61 \%$ \\
Loss of interest & 131 & $40.06 \%$ \\
Indecisiveness & 117 & $35.77 \%$ \\
Worthlessness & 104 & $31.80 \%$ \\
Loss of energy & 95 & $29.05 \%$ \\
Changes in sleep Pattern & 128 & $39.14 \%$ \\
Irritability & 122 & $37.3 \%$ \\
Change in appetite & 110 & $33.63 \%$ \\
Concentration difficulties & 83 & $25.38 \%$ \\
Tiredness & 58 & $17.73 \%$ \\
Loss of interest in sex & 88 & $26.91 \%$ \\
\hline
\end{tabular}

As it is displayed from the above table, symptoms of depression were revealed with their score and percentage depending on the Beck depression inventory scale. Accordingly, the above table reveals the symptoms that prevail among inmates of Bonga Town correctional center. With this regard, the major symptoms that prevail among inmates of Bonga Town correctional center with their count were self-criticalness 196(59.93\%), self-dislike $189(57.79 \%)$ and tiredness (17.73\%) with the least prevalent symptom in Bonga correctional center.

Table 2. Level of depression among inmates of Bonga Town correctional center. $\mathrm{N}=327$

\begin{tabular}{lcc}
\hline \multicolumn{1}{c}{ BDI Score } & Frequency & Percentage \\
\hline $0-13$ (normal) & 36 & 11 \\
$14-19$ (mild) & 40 & 12.23 \\
$20-28$ (moderate) & 171 & 52.29 \\
$29-63$ (sever) & 80 & 24.46 \\
Total & 327 & 100 \\
\hline
\end{tabular}

The above table revealed the level of depression among inmates of Bonga Town correction center. Hence, according to the Beck Depression Inventory, the level of depression is determined according to a cut-off point which is displayed in the above table. Therefore, depending on the above table the majority of inmates in Bonga correctional center falls on mild to moderate. However, most respondents fall under a moderate level of depression $(52.29 \%)$. 
Table 3. Association of inmates years of incarceration and depression

\begin{tabular}{lllll}
\hline \multicolumn{2}{l}{ Independent variable(IV) } & Pessimism & Self-dislike & Crying \\
\hline YI & $R$ & $.120^{*}$ & $.136^{*}$ & $.142^{*}$ \\
& $p$-value & .030 & .014 & .010 \\
& $\mathrm{~N}$ & 327 & 327 & 327 \\
\hline
\end{tabular}

* Correlation is significant at the 0.05 level (2-tailed).

$\mathrm{YI}=$ Year of incarceration, $\mathrm{N}=$ Number of the sample.

The above table reveals the relationship between year of incarceration and depression; hence, symptoms of depression were determined (as measured by BDI-II scale) and the correlation was investigated by using the Pearson product-moment correlation coefficient. Based on this, the symptoms that were statistically significant are pessimism $(\mathrm{r}=.120, p=030)$, self-dislike $(r=.136$, $p=.014)$ and crying $(r=.142, p=.010)$ respectively.

Table 4. Stepwise Regression on major factors responsible for the depression (sadness).

\begin{tabular}{lcc}
\hline Predictor Variable & Beta & p-value \\
\cline { 2 - 3 } & & \\
$\begin{array}{l}\text { Not having a good attitude toward } \\
\text { oneself }\end{array}$ & .250 & $.000^{*}$ \\
$\begin{array}{l}\text { Gender } \\
\text { Ethnicity }\end{array}$ & .132 & $.015^{*}$ \\
\end{tabular}

\section{*significant at $\mathrm{p}=.05$}

The stepwise regression result revealed that the underlying and significant factors for depression. Hence, significant factors were displayed for each symptom. Furthermore, the level of significance for each factor was seen at $95 \%$ CI. In relation to this symptom of sadness at $95 \%$ CI was not having a good attitude to oneself $(\mathrm{B}=.250, \mathrm{p}=.000)$, gender $(\mathrm{B}=.132, \mathrm{p}=.015)$ and Ethnicity $(B=-.107, p=046)$.

Table 5. Stepwise Regression on major factors responsible for the depression (Pessimism)

\begin{tabular}{lll}
\hline Predictor variable & Beta & p-value \\
\cline { 2 - 3 } & & \\
\hline Marital status & .286 & $.000^{*}$ \\
not having a good & .228 & $.000^{*}$ \\
attitude toward oneself & & \\
Educational level & .181 & $.000^{*}$ \\
Gender & .125 & $.015^{*}$ \\
Being discriminated & -.108 & $.034^{*}$ \\
\hline
\end{tabular}

*Significant at $\mathrm{p}=.05$ 
As observed from the table, the underlying factors for being pessimistic are displayed. Hence, stepwise regression analysis revealed that at 95\% CI significant factors, such as marital status $(\mathrm{B}=.286, \mathrm{p}=.000)$, not having good attitude toward oneself, $(\mathrm{B}=.228, \mathrm{p}=.000)$, Educational level, $(\mathrm{B}=.181, \mathrm{p}=.000)$, Gender, $(\mathrm{B}=.125, \mathrm{p}=.015)$, and being discriminated, $(\mathrm{B}=-.108, \mathrm{p}=.034)$.

Table 6. Stepwise Regression on major factors responsible for the depression (past failures)

\begin{tabular}{ccc} 
Predictor variable & Beta & p-value \\
\hline Ethnicity & -.210 & $.000^{*}$ \\
Gender & -.181 & $.001^{*}$ \\
Lack of privacy & .201 & $.000^{*}$ \\
Not having a good attitude toward oneself & -.126 & $.016^{*}$ \\
\hline
\end{tabular}

*significant at $\mathrm{p}=.05$

As it is observed from the above table, there are underlying factors for past failure. Hence, below-mentioned factors are significant at $95 \% \mathrm{CI}$ and $99 \% \mathrm{CI}$. These factors are Ethnicity, $(\mathrm{B}=-$ $.210, \mathrm{p}=.000)$, Gender, $(\mathrm{B}=-.181, \mathrm{p}=.001)$, lack of privacy, $(\mathrm{B}=.201, \mathrm{p}=.000)$, Not having good attitude toward oneself, $(\mathrm{B}=-.126, \mathrm{p}=.016)$.

Table 7. Stepwise Regression on major factors responsible for the depression (Loss of pleasure)

\begin{tabular}{lll} 
Predictor Variable & Beta & p-value \\
\hline Gender & -.133 & $.015^{*}$ \\
Ethnicity & -.119 & $.029^{*}$ \\
Being new to a & -.158 & $.006^{*}$ \\
correctional center & & \\
Lack of privacy & .132 & $.022^{*}$ \\
\hline *significant at $\mathrm{p}=.05$ & &
\end{tabular}

As displayed from the above table factors that were underlying and significant according to stepwise regression were for the symptoms of depression (loss of pleasure at $95 \% \mathrm{CI}$ ) were the following; gender $(\mathrm{B}=-.133, \mathrm{p}=.015)$, Ethnicity, $(\mathrm{B}=-.119, \mathrm{p}=.029)$, Being new to correctional center, $(\mathrm{B}=-.158, \mathrm{p}=.006)$ and lack of privacy, $(\mathrm{B}=.132, \mathrm{p}=.022)$.

Table 8. Stepwise Regression on major factors responsible for the depression (Guilty feeling)

\begin{tabular}{lll}
\hline Predictor Variable & Beta & p-value \\
\hline Educational level & -.127 & $.020^{*}$ \\
Not having good thought? & -.188 & $.001^{*}$ \\
Isolation from social life & -.137 & $.011^{*}$ \\
Age & .130 & $.016^{*}$ \\
Year of incarceration & .107 & $.047^{*}$ \\
\hline
\end{tabular}

*significant at $\mathrm{p}=.05$

In spite, from the above table, the underlying factors for guilty feeling are displayed by stepwise regression analysis. Hence, the factors that have a significant contribution to the $95 \% \mathrm{CI}$, are the following. Educational level, $(\mathrm{B}=-.127, \mathrm{p}=.20)$, not having good thought, $(\mathrm{B}=-.188, \mathrm{p}=.001)$, 
isolation from social life, $(B=-.137, p=.011)$, age, $(B=.130, p=.016)$ and year of incarceration, $(B=$ $.107, \mathrm{p}=.047)$.

Table 9. Stepwise Regression on major factors responsible for the depression (punishment feeling)
Predictor variable
Beta
P-value.

Marital status

.185

$.001 *$

not having hope to get an excuse

$-.109$

$.045^{*}$

$*$ Significant at $\mathrm{p}=.05$

The predicted factors which are categorized under socio-demographic factors were marital status $(B=.185, p=.001)$ and not having hope to get an excuse $(B=-.109, p=.045)$ predicted factors for symptoms of punishment feeling.

Table 10. Stepwise Regression on major factors responsible for the depression (Self-Dislike)

\begin{tabular}{lll} 
Predictor variable & Beta & p-value \\
\hline Marital status & .238 & $.000^{*}$ \\
Little or no social support & -.127 & $.019^{*}$ \\
Is there any impossibility that prevents & -.166 & $.001^{*}$ \\
you to resettle to the previous state? & & $.015^{*}$ \\
Ethnicity & .124 & $.019^{*}$ \\
Torture/ Maltreatment & -.121 & $.005^{*}$ \\
Being new to a correctional center & .149 & $.024^{*}$ \\
Isolation from social life & -.127 & \\
\hline
\end{tabular}

*significant at $\mathrm{p}=.05$

As it is displayed from the above table, factors that contribute inmates in Bonga Town correctional center to have to feel of self-dislike at 95\% CI accordingly were the following: marital status $(\mathrm{B}=.238, \mathrm{P}=.000)$, little or no social support $(\mathrm{B}=-.127, \mathrm{P}=.019)$, impossibilities that prevent to resettle to the previous state $(\mathrm{B}=-.166, \mathrm{P}=.001)$, Ethnicity $(\mathrm{B}=.124, \mathrm{P}=015)$, Torture $(\mathrm{B}=-$ $.121, \mathrm{P}=.019)$, being new to correctional center $(\mathrm{B}=.149, \mathrm{P}=.005)$ and isolation from social life $(\mathrm{B}=-$ $.127, \mathrm{P}=.024)$.

Table 11. Stepwise Regression on major factors responsible for the depression (Self-Criticalness)

\begin{tabular}{lcl}
\hline Predictor variable & Beta & p-value \\
\hline Ethnicity & -.192 & $.000^{*}$ \\
Little or no social support & .207 & $.000^{*}$ \\
Family history of mental illness & -.189 & $.001^{*}$ \\
\hline
\end{tabular}

*significant at $\mathrm{p}=.05$

As it is observed from the table, factors that are related with self-criticalness among inmates of Bonga Town correctional center at $95 \%$ CI were contributing and underlying factors of depression are listed below depending on the results of stepwise regression are; Ethnicity $(B=-.192$, 
$\mathrm{P}=.000, \mathrm{p}<.001)$, little or no social support $(\mathrm{B}=.207, \mathrm{P}=.000)$, family history of mental illness $(\mathrm{B}=$ $.189, \mathrm{P}=.001, \mathrm{p}<.05)$.

Table 12. Stepwise Regression on major factors responsible for the depression (Suicidal Thoughts)

\begin{tabular}{lll}
\hline Predictor variable & Beta & p-value \\
\cline { 2 - 3 } & & \\
\hline Marital status & .255 & $.000^{*}$ \\
Gender & -.203 & $.000^{*}$ \\
Age & .161 & $.001^{*}$ \\
Low satisfaction of service & -.137 & $.009^{*}$ \\
delivery with prison & & \\
Overcrowding & .153 & $.003^{*}$ \\
Isolation from social life & -.150 & $.007^{*}$ \\
Presence of violence & .134 & $.015^{*}$ \\
Ethnicity & .102 & $.043^{*}$ \\
\hline
\end{tabular}

*Significant at $\mathrm{p}=.05$

As displayed from the above table, factors for suicidal thought at $95 \% \mathrm{CI}$ are mentioned below. Marital status $(B=.255, \mathrm{p}=.000)$, gender $(\mathrm{B}=-.203, \mathrm{p}=.000)$, age $(\mathrm{B}=.161, \mathrm{p}=.001)$, Low satisfaction of service delivery with prison $(\mathrm{B}=-.137, \mathrm{p}=.009)$, overcrowding $(\mathrm{B}=-.153, \mathrm{p}=.003)$, isolation from social life $(B=-.150, p=.007)$, presence of violence $(B=.134, p=.015)$, and ethnicity $(\mathrm{B}=.102, \mathrm{p}=.043)$, respectively are factors that contribute suicidal thought among inmates of Bonga Town correctional center. Hence, from the above table major factors responsible for the crying among inmates of Bonga Town correctional center at 99\% CI, are listed below. Marital status $(\mathrm{B}=$ $.287, \mathrm{p}=.000)$, and ethnicity $(\mathrm{B}=.234, \mathrm{p}=.000)$ respectively. In addition to the above table, the results of stepwise regression analysis relvealed that factors that contribute inmates to lose their interest in Bonga Town correctional center at 95\% CI and 99\% CI, are the following: marital status $(\mathrm{B}=$ $.494, \mathrm{p}=)$, and not being happy with life until being inmates $(\mathrm{B}=.099, \mathrm{p}=.040)$.

Table 13. Stepwise Regression on major factors responsible for the depression (Feeling of worthlessness)

\begin{tabular}{lcc}
\hline Predictor variable & Beta & p-value \\
\hline Ethnicity & .130 & $.018^{*}$ \\
Marital status & .109 & $.049^{*}$
\end{tabular}

*Significant at $\mathrm{p}=.05$

As it is displayed on the above table, major factors that are responsible for the feeling of worthlessness among inmates of Bonga Town correctional center depending on the stepwise regression analysis at $95 \% \mathrm{CI}$ are the following: ethnicity $(\mathrm{B}=.130, \mathrm{p}=.018)$, and marital status $(\mathrm{B}=.109, \mathrm{p}=.049)$.

Table 14. Stepwise Regression on major factors responsible for the depression (Irritability)

\begin{tabular}{cll}
\hline Predictor Variable & Beta & p-value \\
\hline Is there violence? & -.203 & $.000^{*}$ \\
Do you have Self-confidence? & .150 & $.006^{*}$ \\
\hline
\end{tabular}




\begin{tabular}{lll}
\hline Age & .135 & $.013^{*}$ \\
Lack of privacy & .122 & $.036^{*}$ \\
\hline
\end{tabular}

*Significant at $\mathrm{p}=.05$

As it is displayed from the table, factors that contribute inmates of Bonga Town correctional center to be irritable according to stepwise regression result at $95 \% \mathrm{CI}$, are existence of violence among inmates $(B=-.203, p=.000)$, not having Self-confidence $(B=.150, p=.006)$, age $(B=$ $.135, \mathrm{p}=.013)$, and lack of privacy $(\mathrm{B}=.122, \mathrm{p}=.036)$, are respective factors that are related to irritability.

Table 15. Stepwise Regression on major factors responsible for the depression (Change in appetite)

Predictor variable Beta p-value

\begin{tabular}{lll} 
Do you have Self-confidence? & .174 & $.001^{*}$ \\
Gender & .131 & $.015^{*}$ \\
Torture / Maltreatment & -.117 & $.030^{*}$ \\
Age & .132 & $.014^{*}$ \\
Is there violence? & -.106 & $.050^{*}$ \\
\hline
\end{tabular}

*significant at $\mathrm{p}=.05$

From the table results of stepwise regression analysis revealed, factors that contribute inmates in Bonga correctional center to have change in appetite in Bonga Town correctional center at 95\% $\mathrm{CI}$ are the following: not having Self-confidence $(\mathrm{B}=.174, \mathrm{p}=.001)$, gender $(\mathrm{B}=.131, \mathrm{p}=.015)$, torture/maltreatment $(B=-.117, p=.030)$, age $(B=.132, p=.014)$ and presence of violence $(B=-.106$, $\mathrm{p}=.050)$.

Table 16. Stepwise Regression on major factors responsible for the depression (Concentration Difficulties)

\begin{tabular}{lll}
\hline Predictor variable & Beta & p-value \\
\hline Gender & .176 & $.001^{*}$ \\
The impossibility that prevents to resettle to the previous state? & .124 & $.022^{*}$ \\
Isolation from social life & .199 & $.001^{*}$ \\
Family history of mental illness & -.141 & $.013^{*}$ \\
Being new to correctional center & -.127 & $.022^{*}$ \\
$\quad$ Not having Self-confidence & .132 & $.018^{*}$ \\
Ethnicity & -.120 & $.026^{*}$ \\
\hline
\end{tabular}

*significant at $\mathrm{p}=.05$

As displayed from the above table factors that contribute inmates of Bonga Town correctional center to have concentration difficulties according to stepwise regression result at $95 \%$ $\mathrm{CI}$ are Gender $(\mathrm{B}=.176, \mathrm{p}=.001)$, Impossibility that prevents to resettle to the previous state? $(\mathrm{B}=.124, \mathrm{p}=.022)$, Isolation from social life $(\mathrm{B}=.199, \mathrm{p}=.001)$, Family history of mental illness $(\mathrm{B}=-$ $.141, \mathrm{p}=.013)$, Being new to correctional center $(\mathrm{B}=-.127, \mathrm{p}=.022)$, not having Self-confidence $(\mathrm{B}=.132, \mathrm{p}=.018)$ and Ethnicity $(\mathrm{B}=-.120, \mathrm{p}=.026)$. 
Table 17. Stepwise Regression on major factors responsible for the depression (Tiredness or fatigue)

\begin{tabular}{lcc}
\hline Predictor variable & Beta & p-value \\
\hline Marital status & -.237 & $.000^{*}$ \\
Not having Self-confidence & .205 & $.000^{*}$ \\
Being Discriminated & .187 & $.000^{*}$ \\
Gender & .164 & $.002^{*}$ \\
Not having a good attitude to yourself? & -.123 & $.017^{*}$ \\
Presence of violence & -.109 & $.034^{*}$ \\
\hline
\end{tabular}

*significant at $\mathrm{p}=.05$

According to the table, the results of stepwise regression analysis revealed, factors that contribute inmates to have feeling of tiredness in Bonga Town correctional center at $95 \% \mathrm{CI}$ are the following: marital status $(\mathrm{B}=-.237, \mathrm{p}=.000)$, not having Self-confidence $(\mathrm{B}=.205, \mathrm{p}=.000)$, discriminated $(\mathrm{B}=.187, \mathrm{p}=.000)$, Gender $(\mathrm{B}=.164, \mathrm{p}=.002)$, not having good attitude to yourself $(\mathrm{B}=$ $-.123, \mathrm{p}=.017)$ and presence of violence $(\mathrm{B}=-.109, \mathrm{p}=.034)$.

Table 18. Stepwise Regression on major factors responsible for the depression (Loss of interest in sex)

\begin{tabular}{llc}
\hline Predictor variable & Beta & p-value \\
\hline Not having a good attitude to yourself & -.159 & $.004^{*}$ \\
Being Discriminated & .136 & $.013^{*}$ \\
Educational level & -.129 & $.019^{*}$ \\
Not having a good thought & .124 & $.024^{*}$ \\
\hline
\end{tabular}

*significant at $\mathrm{p}=.05$

As observed from the table stepwise regression analysis has devised major factors responsible for having loss of interest in sex among inmates of Bonga Town correctional center at 95\% CI, were the following not having good attitude to yourself $(\mathrm{B}=-.159, \mathrm{p}=.004)$, Discriminated $(\mathrm{B}=.136, \mathrm{p}=.013)$, Educational level $(B=-.129, \mathrm{p}=.013)$ and not having good thought $(\mathrm{B}=.124, \mathrm{p}=.024)$. 


\begin{tabular}{|c|c|c|c|c|c|}
\hline \multirow[t]{2}{*}{ Symptoms of Depression } & \multicolumn{2}{|c|}{ Frequency } & \multirow[t]{2}{*}{$\mathrm{Z}$} & \multirow[t]{2}{*}{ p-value } & \multirow{2}{*}{$\begin{array}{l}\text { Table } \\
19 . \\
\text { Mann }\end{array}$} \\
\hline & Male & Female & & & \\
\hline Sadness & 99 & 39 & -3.187 & $.001 *$ & Whitne \\
\hline Pessimism & 27 & 71 & -2.759 & $.006 *$ & y U \\
\hline Past failures & 82 & 11 & -4.316 & $.000 *$ & test for \\
\hline Loss of pleasure & 43 & 98 & -3.658 & $.000 *$ & gender \\
\hline Guilty feeling & 99 & 47 & -.183 & .854 & differe \\
\hline Punishment feeling & 49 & 12 & -1.356 & .175 & nce on \\
\hline Self-dislike & 168 & 21 & -.860 & .390 & \\
\hline Self-criticalness & 139 & 57 & -1.169 & .242 & sympto \\
\hline Suicidal thoughts or wishes & 96 & 17 & -4.219 & $.000 *$ & ms of \\
\hline Crying & 23 & 80 & -.691 & .489 & depress \\
\hline Agitation & 90 & 33 & -.212 & .832 & ion \\
\hline loss of interest & 88 & 43 & -.247 & .805 & $(\mathrm{~N}=32$ \\
\hline Indecisiveness & 22 & 95 & -.100 & .921 & 7 \\
\hline Worthlessness & 49 & 55 & -.697 & .486 & $M=221$ \\
\hline loss of energy & 33 & 62 & -2.369 & $.018 *$ & \\
\hline Changes in sleep Pattern & 48 & 80 & -.870 & .384 & $F=106)$ \\
\hline Irritability & 43 & 73 & -2.211 & $.027 *$ & \\
\hline Change in appetite & 89 & 21 & -2.985 & $.003 *$ & \\
\hline Concentration Difficulties & 33 & 50 & -2.763 & $.006 *$ & \\
\hline Tiredness & 19 & 39 & -3.457 & $.001 *$ & \\
\hline Loss of interest in sex & 79 & 9 & -.346 & .729 & \\
\hline
\end{tabular}




\section{*significant at $\mathrm{p}=.05$}

An examination of the findings in the above table displays that the results of Mann Whitney $\mathrm{U}$ test applied to compare the symptoms of depression across gender. Based on this symptom that is statistically significant were mentioned below. Therefore, sadness $(Z=-3.187, p=.001)$. The frequency revealed that more male inmates feel sadder than female inmates. Pessimism $(Z=-2.759$, $\mathrm{p}=.006)$. The frequency revealed that more female inmates feel pessimistic than male inmates. Past failure $(Z=-4.316, p=.000)$. The frequency revealed that more male inmates have past failures than female inmates. Loss of pleasure $(Z=-3.658, p=.000)$. The frequency revealed that more female inmates have a loss of pleasure than male inmates. Suicidal thought $(Z=-4.219, p=.000)$. The frequency revealed that more male inmates have a feeling of suicidal thoughts than female inmates. Loss of energy $(Z=-2.369, p=.018)$. The frequency revealed that more female inmates have a feeling of loss of energy than male inmates. Irritability $(Z=-2.211, p=.027)$. The frequency revealed that a female inmate's feel irritated than male inmates. Change in appetite $(Z=-2.985, p=.003)$. The frequency revealed that more male inmates had a change in appetite than female inmates. Concentration difficulties $(\mathrm{Z}=-2.763, \mathrm{p}=.006)$. As observed from the count more female inmates have concentration difficulties than male inmates and tiredness $(Z=-3.457, p=.001)$. The high frequency reveals more female inmates had a feeling of tiredness or fatigue than male inmates.

Generally, a difference between male and female in relation to the effects of imprisonment.

Hence, according to (Ulzen, Psych \& Hamilton, 1998, p.57-63), gender differences exist with respect to the effects of incarceration on both male and female inmates. Mental health problems have been observed to be higher among incarcerated inmates compared to the general population and are a significant source of morbidity among inmates (Fatoye, Oyebanji, \& Ogunro, 2006, p.545).

\section{Discussion}

The finding of this study revealed that symptoms of depression prevail among inmates of Bonga Town correctional center. As it is measured by the Beck Depression Inventory, symptoms that exist among inmates of Bonga correctional center were: self-criticalness and self-dislike. This may be due to the criminal offense they made, violence in the correction. Inconsistency with this, the previous research finding revealed that symptoms of depression prevail in prison. For instance, a study conducted in a Nigerian prison revealed that the prevalence of depressive symptom was high (Nwaopara \& Stanley, 2015, p.5).

In this study, the descriptive statistics result particularly the frequency and percentage revealed the level of depression among inmates ranges from mild to severe level of depression. However, most inmates fall on a moderate level of depression (52.29\%). Inconsistent with this the previous studies showed that the level of depression is high with an extension from mild to severity level. For instance, the level of depression in Pakistan among inmates was 85\% according to (Aftab, Diego, Yousaf, Corporation, \& Hashmi, 2014) and the majority of inmates fall under moderate level. However, in contrast to this, the finding on the level of depression in Nigerian prison revealed that the level of depression is $33.5 \%$ (Uche \& Princewill, 2015, p.345). Hence, this variation may be due to variation in cut-off point, and even if the instruments are the same but the cut-off point used in this study was not representatives. 
Regarding the association between years of incarceration and depression, the finding of this study revealed that there was an almost little association between the symptoms of depression and years of incarceration. Hence, symptoms of depression that have significant relation with years if incarceration were pessimism $(r=.120, \mathrm{p}=.030)$, self-dislike $(r=.136, \mathrm{p}=.014)$ and crying $(r=.142$, $p=.010$ ). However, this relationship occurs due to an increase in the rate of incarceration, an increase in the number of life sentences and death penalties, overcrowded correctional living, tortured in prison. Related to this, different research revealed approximate findings to this study. For instance, research conducted among inmates of New South Wales, Australia revealed one third of inmates do not like themselves and attempt to make suicide in the correctional center (Larney, Topp, Indig, Driscoll \& Greenberg, 2012, p.23).

In this study to determine the underlying factors for depression, stepwise regression was employed. Hence, the finding revealed different factors for the symptoms of depression. These are marital status, ethnicity, gender, age, not having a good attitude towards oneself and others, lack of privacy, being new to the correctional center, the presence of violence and being discriminated. However, the most frequent factors were not having a good attitude toward oneself/others, marital status, little social support and lack of self-confidence. In spit, inmates in Bonga town correctional center hold less attitude toward themselves due to looking oneself as criminal, may not have acceptance from inside of prison and outside from general population, etc.. Beyond to that majority of inmates in Bonga correctional center were divorced with their couples. Related research findings from Iranian inmate $s$ revealed marital status as a risk factor for depression among prisoners, particularly divorced inmates are at high risk of depression (Sepehrmanesh, Ahmadvand, Akasheh \& Saei, 2014,pp.12-13).

\section{Conclusion}

The objective of this study was to explore the symptoms and underlying factors of depression among inmates in Bonga Town correctional center. The frequent symptoms of depression that prevailed among inmates of Bonga Town correctional center were sadness, pessimism, past failures, loss of pleasure, guilty feeling, punishment feeling, self-dislike, self-criticalness, suicidal thoughts or wishes, crying, agitation and loss of interest. The major symptoms of depression were selfcriticalness/self-dislike. The level of depression among inmates of Bonga correctional center ranges from mild to severe level of depression. Further, most inmates in Bonga correctional center were moderately depressed. Among the symptoms of depression that has a significant association with inmates years of incarceration were pessimism, self-dislike and crying. Factors that are related with depression among inmates of Bonga Town correctional center were sociodemographic factors (i.e. marital status, ethnicity, gender and age), psychosocial factors (i.e. not having good attitude-toward oneself and others, presence of violence and being discriminated) and environmental factors (i.e.lack of privacy and being new to correctional center). In addition, there was a significant difference between males and females regarding the symptoms of depression; hence, female inmates were more depressed than male inmates. Symptoms of sadness, past failure, suicidal thought and change in appetite, pessimism, loss of pleasure, loss of energy, irritability, concentration difficulties, and tiredness were depressive symptoms that made a statistically significant difference between male and female inmates in Bonga correctional center. 


\section{Recommendations}

Based on these main findings of this study, the researcher forwarded the following suggestions:

Depression was the most serious problem for inmates in Bonga Town correctional center; therefore, Health professionals who were working in Bonga G/Tsadik Shawo hospital should give training on awareness development to communities of Bonga correctional center including police officers, police commanders, and correctional administrators to understand and help inmates who have symptoms of depression.

In order to deal with these serious problems the office of social workers such as a counselor, sociologists always should be open and they should have to encourage inmates to communicate with them when the symptoms frequently occur on them.

Bonga correctional center community should help inmates to develop a social life and to communicate freely on problems that they face in Bonga correctional center.

As being divorced is the main factor, Bonga correctional center administrators should invite and work with a marriage counselor. Further, strengthening the linkage between Bonga correctional center and Bonga G/Tsadik Shawo hospital is recommended to solve these serious problems easily. Further study should be done by covering a wide range of samples from different correctional centers in different geographical locations and by including variables that were not included in this study like religion, residence, economic status, etc.

\section{Acknowledgment}

We would like to thank data collectors for their invaluable effort. Our gratitude also goes to the study participants who were volunteered and took their time to provide us all the relevant information for the study.

\section{Competing interest}

The authors have declared that there are no competing interests.

\section{References}

Aftab, A., Diego, S., Yousaf, Z., Corporation, H. M., \& Hashmi, A. M. (2014). Prevalence of Depression among Male Prisoners at an Urban Jail in Pakistan, (June).

Araoye, M (2003).Research Methodology with statistics for health and social sciences, Nathadex publishers 115-129.

Birmingham L. (2004). Mental disorder and prisons. Psychiatr Bull 2004;28:393-7. BMC psychiatry, 12(1), 237. 
Drapalski AL, Youman K, Stuewig J, Tangney J (2009). Gender differences in jail inmates' symptoms of mental illness, treatment history and treatment seeking. Crim Behav Ment Health 2009;19:193-206.

Fatoye, F. O., Fatoye, G. K., Oyebanji, A. O., \& Ogunro, A. S. (2006). Psychological character.

Fazel S, Danesh J.( 2002). Serious mental disorder in 23000 prisoners: a systematic review of 62 surveys. Lancet.;359(9306):545-50.

Fazel S, Seewald K (2012).Severe mental illness in 33588 prisoners worldwide: systematic review and meta-regression analysis. Br J Psychiatry.;200(5):364-73.

Kothari,C.(2004).Research methodology:methods and techniques.New Age International. https://doi.org/http://196.29.172.66:8080/jspui/bitstream/123456789/2574/1/Research20 Methodology.pdf.

Larney, S., Topp, L., Indig, D., O’Driscoll, C., \& Greenberg, D. (2012). A cross-sectional survey of prevalence and correlates of suicidal ideation and suicide attempts among prisoners in New South Wales, Australia. BMC Public Health, 12, 14. http://doi.org/10.1186/1471-2458-12-14.

Lemma, S., Gelaye, B., Berhane, Y., Worku, A., \& Williams, M. A. (2012). Sleep quality and its medical journal, 83(10), 545.

Ministry of Home Affairs, (2016). Department of Prison Management. Nepal. Available at: http://www.dopm.gov.np/. Accessed 15 Feb 2016.

Mossie, A., Kindu, D., \& Negash, A. (2016). Prevalence and Severity of Depression and It's association with Substance Use in Jimma Town, Southwest Ethiopia. Depression research and treatment,2016. https://doi.org/10.1155/2016/3460462.

National Academy on An Aging Society. (2000). Depression a Treatable Disease.

National Institute of Mental Health. (2003). Depression and college students.

Nwaopara U, Stanley P (2015) Prevalence of Depression in Port Harcourt Prison. J Psychiatry 18: 340 doi:10.4172/2378-5756.1000340 privação da liberdade. Rev. enferm. UERJ, 418-424.

Psychiatric disorders in New Zealand prisons: a national study. Australian and New Zealand Journal of Psychiatry, 35(2), 166-173.

Psychological correlates among university students in Ethiopia: a cross-sectional study.

Sepehrmanesh, Z., Ahmadvand, A., Akasheh, G., \& Saei, R. (2014). Prevalence of Psychiatric Disorders and Related Factors in Male Prisoners. Iranian Red Crescent Medical Journal, 16(1), e15205. http://doi.org/10.5812/ircmj.15205.

The World Health Organization report on mental health: new understanding. New hope. 2001. https://www.who.int/ whr/2001/en/. Accessed 04 Feb 2019. 
Uche N, Princewill S. (2015). Clinical Factors as Predictors of Depression in a Nigerian Prison Population. J Psychiatry 19: 345 doi: 10.4172/2378-5756.1000345.

Ulzen TP, Hamilton H.(1998). The nature and characteristics of psychiatric comorbidity in incarcerated adolescents. Can J Psychiatry 43: 57-63.

Walmsley R. (2013). World prison population list 10th edition. International Center for Prison. Studies. Available at: http://www.prisonstudies.org; Accessed 15 Feb 2016.

WHO. (2007). Mental health and prisons. Geneva. World Health Organization; Available at: http://www.who.int/mental_health/policy/services/en/index. html. Accessed 15 Feb 2016.

WHO. (2016). Trencin statement on prisons and mental health. WHO Europe. 2008. Available at: http://www.euro.who.int/_data/assets/pdf_file/0006/99006/ E91402.pdf. Accessed 15 Feb 2016.

World Health Organization. (2010).The World Health Report Mental Health: New Understanding, New Hope.

\section{Copyrights}

Copyright for this article is retained by the author(s), with first publication rights granted to the journal. This is an open-access article distributed under the terms and conditions of the Creative Commons Attribution license (http://creativecommons.org/licenses/by/4.0/). 